\title{
Grain Size Control of Tetragonal Zirconia Polycrystals Using the Space Charge Concept
}

\author{
Shyh-Lung Hwang* and I-Wei Chen* \\ Department of Materials Science and Engineering, University of Michigan. \\ Ann Arbor, Michigan 48109-2136
}

Grain growth kinetics and grain-boundary segregation of 12Ce-TZP and 2Y-TZP, containing divalent to pentavalent cationic dopants, were studied. In all cases, normal grain growth following the parabolic growth relation was observed at higher temperatures. The mobility of grain boundaries was suppressed by the addition of divalent and trivalent cations, unchanged or enhanced by the addition of tetravalent and pentavalent cations. Larger cations have a stronger effect in suppressing grain growth. From ESCA, AES, and STEM analysis of the near grain-boundary regions, it is further concluded that only divalent and trivalent cations segregate. These observations can be satisfactorily rationalized using the space charge concept and the model of impurity drag. [Key words: grain growth, tetragonal zirconia polycrystals, segregation, grain boundaries, dopants.]

\section{Introduction}

I N THE space charge theory of Frenkel, ${ }^{1}$ later extended by Eshelby, Koehler, and their co-workers, ${ }^{2,3}$ surfaces, grain boundaries, and dislocation cores in an ionic crystal are predicted to possess a net charge and to have a region of space charge of the opposite sign adjacent to these lattice discontinuities. While in theory the types of surface and space charges are dependent on the formation energies of point defects (vacancies and interstitials) in pure ionic crystals, it is more likely, as in almost all practical cases, that they are dictated by the effective charge of the aliovalent impurities. Physically, if dopants of a positive (negative) effective charge are present in the bulk, then the surface, in thermal equilibrium, must possess a countercharge which is negative (positive). The dopants, in turn, must segregate to the region adjacent to the surface as a space charge so that the bulk of the crystal remains essentially neutral. The role of Schottky defects is merely one which mediates the above solid "electrolyte," although any tendency toward binding between point defects and dopants to form neutral complexes can sharply reduce both the surface and the space charge. ${ }^{3}$ Experimental evidence for the above behavior, the most definitive one being found in alkali halides, has been previously reviewed by Kingery. ${ }^{4}$ In comparison, systematic studies of such effects in oxides have been lacking, although some limited data exist in $\mathrm{MgO}^{5,6}$ and $\mathrm{Al}_{2} \mathrm{O}_{3}{ }^{7}$

Tetragonal zirconia polycrystals (TZPs) are a class of distorted fluorite structure oxide ceramic which have an appreciable solubility, of the order of a few percent, for a large number of cationic dopants. The majority of such dopants are

D. M. Smyth - contributing editor

Manuscript No. 198024. Received October 27, 1989; approved June 15, 1990.

Supported by the Air Force Office of Scientific Research under Grant No. 87-0289.

${ }^{\star}$ Member, American Ceramic Society. divalent and trivalent cations which also serve as tetragonal stabilizers. According to the space charge theory outlined above, they are expected to segregate to grain boundaries. If so, they may also exert a solute drag on the motion of grain boundaries. Inasmuch as grain size control is an essential tool for tailoring mechanical properties of transformationtoughened TZPs, with a direct consequence on their compressive strengths, tensile strengths, fracture toughness, superplasticity, and thermal stability, an understanding of the space charge phenomena and their relationship to grain growth is of considerable interest.

We have selected a $\mathrm{Ce}-\mathrm{TZP}$, containing $12 \mathrm{~mol}^{2} \mathrm{CeO}_{2}$, as a base material and studied the effect of a number of dopants on its grain growth and segregation behavior. This base material was chosen because it remained in the single-phase tetragonal field when a small amount of dopants, ranging from divalent to pentavalent cations, were added. To gain further insight into the energetics and kinetics of the segregation and grain growth behavior, dopants of different ionic radia are contrasted. In addition, several other TZPs were studied to further verify the space charge concept.

\section{Experimental Procedure}

High-purity $12 \mathrm{Ce}-\mathrm{TZP} *$ and oxide or carbonate powders were used as starting materials. Except where noted, dopant concentrations were fixed at $1 \%$ substitution of the total cation sites. The powder mixtures of $12 \mathrm{Ce}-\mathrm{TZP}$ and the designated amount of additive oxides were attrition-milled in an alumina jar using zirconia milling media with a polyelectrolyte. The milled slurry was cast, under a pressure of up to $1 \mathrm{MPa}$, into cakes with a diameter of $47 \mathrm{~mm}$, which were dried and isostatically pressed at $400 \mathrm{MPa}$. The green density after isopressing was between $60 \%$ to $65 \%$ of the theoretical density. Samples of 2Y-TZP and other TZPs were prepared similarly, except for a smaller dopant concentration of $0.6 \%$ substitution of the total cation sites when specified.

Sintering was performed in air at a constant heating rate of $10^{\circ} \mathrm{C} / \mathrm{min}$ up to the desired temperatures, held there from 3 to $70 \mathrm{~h}$, and then cooled in the furnace. In the case of indium additions, samples were packed in powders of the same compositions to reduce the effect of indium volatization. The density of the sintered specimen was determined by a water immersion method and the phase content was analyzed by $\mathrm{X}$-ray diffractometry. For grain growth studies, only samples of a density better than $99 \%$, and of $100 \%$ tetragonal phase, were used.

To reveal the grain boundaries, thermal etching for $5 \mathrm{~min}$ at $50^{\circ} \mathrm{C}$ below the sintering temperature was used. Grain sizes were measured on SEM micrographs by multiplying the average linear intercept of at least 500 grains by 1.5 .

All the specimens could be fractured intergranularly at room temperatures. This feature allowed the use of $\mathrm{X}$-ray photoelectron spectroscopy for chemical analysis (ESCA) of

\footnotetext{
*Tosoh, Tokyo, Japan, with $0.01 \mathrm{wt} \% \mathrm{Na}_{2} \mathrm{O}$ and 0.009 wt $\% \mathrm{SiO}_{2}$.
} 
the grain boundaries. A Perkin-Elmer PHI 5400 ESCA $^{\dagger}$ with $\mathrm{Mg}$ and $\mathrm{Al}$ targets was used. Since the ESCA signals came primarily from elements on and within a distance of 1 to $2 \mathrm{~nm}$ from the surface, such measurements are representative of the near grain-boundary compositions. To determine the depth distribution of the composition, argon ion beam sputtering, at $3 \mathrm{kV}$ and $10 \mathrm{~mA} / \mathrm{mm}^{2}$, was applied to progressively remove the near grain-boundary materials. Auger electron spectroscopy (AES) was similarly performed using a JEOL JAMP $30, \ddagger$ operated at low voltages. Scanning transmission electron microanalysis (STEM) of the grain-boundary region was also performed using a JEOL $2000 \mathrm{FX}$ analytical electron microscope ${ }^{\ddagger}$ equipped with a high-angle beryllium-window XEDS detector, ${ }^{\S}$ to complement the ESCA and AES analysis.

\section{Results and Analysis}

\section{(1) Charge, Solubility, and Vegard's Slope}

To evaluate the effect of the ionic size of dopants and the strain energy thereof, lattice constants of $\mathrm{ZrO}_{2}-\mathrm{MO}_{x}$ solid solutions are required. Most data of solubilities and Vegard's slopes of the binary solid solutions in the tetragonal $\mathrm{ZrO}_{2}-$ $\mathrm{MO}_{x}$ phase field are available in the literature or from prior work in our laboratory. ${ }^{10-20}$ When necessary, they have been checked by precision $\mathrm{X}$-ray measurements in this study. These data are summarized in Table I for all the solutes studied here. The reported solubilities are for the tetragonal phase at $1300^{\circ} \mathrm{C}$, and the Vegard's slopes are for the unit-cell volume at room temperature. (Despite the phase change, the unit-cell volume of both the tetragonal and the cubic phase usually follows the same correlation $\Delta V / V_{0}=\alpha C$, where $V_{0}$ is the (extrapolated) volume of pure $\mathrm{ZrO}_{2}, C$ is the mole fraction of solute, and $\alpha$ is the Vegard's slope. ${ }^{21}$ Thus, the data on the unit-cell volume of these two phases have been used interchangeably.) While these data may not be necessarily pertinent for phenomena occurring at other temperatures or for ternary systems, it is obvious that the solutes studied here do cover a broad range of charges, sizes, and solubilities, so that any systematic dependence of segregation and grain growth on these parameters, if it exists, should become apparent from our results. In terms of ionic sizes, among the divalent solutes, $\mathrm{Mg}^{2+}<\mathrm{Ca}^{2+}$; among the trivalent solutes, $\mathrm{Sc}^{3+}<$ $\mathrm{In}^{3+}<\mathrm{Yb}^{3+}<\mathrm{Y}^{3+}$; among the tetravalent solutes, $\mathrm{Ti}^{4+}<$ $\mathrm{Zr}^{4+}<\mathrm{Ce}^{4+}$; among the pentavalent solutes, $\mathrm{Nb}^{5+} \approx \mathrm{Ta}^{5+}$. It is also interesting to note that both $\mathrm{Ca}^{2+}$ and $\mathrm{In}^{3+}$, which have the smallest Vegard's slopes among aliovalent dopants, have the largest solid solubilities. On the other hand, isovalent dopants $\left(\mathrm{Ti}^{4+}\right.$ and $\left.\mathrm{Ce}^{4+}\right)$ all have large solubilities in $\mathrm{ZrO}_{2}$ irrespective of sizes. Clearly, both charge and size mismatch are

Perkin-Elmer, Eden Prairie, MN.

JEOL, Tokyo, Japan.

${ }^{\S}$ Tracor-Northern, Middleton, WI.

Table I. Ionic Radius, Volume Misfit, and Solubility of $\mathrm{MO}_{x}$ in $\mathrm{ZrO}_{2}$

\begin{tabular}{|c|c|c|c|c|}
\hline & $\begin{array}{c}\text { Ionic radius* } \\
(\mathbf{n m})\end{array}$ & Vegard's slope $^{\dagger}$ & $\begin{array}{c}\text { Solubility } \\
\left({\left.\text { mol } \% \mathrm{MO}_{x}^{-}\right)}^{-}\right)\end{array}$ & Ref. \\
\hline $\mathrm{Mg}^{2+}$ & 0.089 & $-0.223(\mathrm{c})$ & 1 & 11 \\
\hline $\mathrm{Ca}^{2+}$ & 0.112 & $0.095(\mathrm{c})$ & 5 & 12 \\
\hline $\mathrm{Sc}^{3+}$ & 0.087 & $-0.113(\mathrm{t})$ & 6 & 13 \\
\hline $\mathrm{In}^{3+}$ & 0.092 & $0.012(\mathrm{t})$ & 9 & 13 \\
\hline $\mathrm{Yb}^{3+}$ & 0.099 & $0.067(\mathrm{t})$ & 5 & 13 \\
\hline $\mathrm{Y}^{3+}$ & 0.102 & $0.077(\mathrm{t})$ & 5 & 14,15 \\
\hline $\mathrm{Ti}^{4+}$ & 0.074 & $-0.172(\mathrm{c})$ & 15 & 16,17 \\
\hline $\mathrm{Ce}^{4+}$ & 0.097 & $0.179(\mathrm{t})$ & 17 & 18,19 \\
\hline $\mathrm{Nb}^{5+}$ & 0.074 & $0.041(\mathrm{t})$ & & 20 \\
\hline $\mathrm{Ta}^{5+}$ & 0.074 & $0.041(\mathrm{t})$ & & 20 \\
\hline
\end{tabular}

*Reference 10, All for 8-fold coordination. Ionic radius of $\mathrm{Zr}^{4+}=$ $0.084 \mathrm{~nm}$. $\Delta V / V_{0}=\alpha C$ ( $\alpha=$ Vegard's slope, $C=$ solute mole fraction, $V_{0}=$ unit-cell volume of pure $\mathrm{ZrO}_{2}$ ). important considerations for tetragonal solubilities in this class of oxides. The lattice contraction in the presence of "oversized" dopants, e.g., $\mathrm{Mg}^{2+}$ and $\mathrm{Sc}^{3+}$, is due to the oxygen vacancies they create.

\section{(2) Grain Size and Grain Growth Kinetics}

Table II illustrates the progression of grain sizes, after sintering at $1400^{\circ} \mathrm{C}$ for $2 \mathrm{~h}$ and annealing at $1420^{\circ} \mathrm{C}$ for $12 \mathrm{~h}$, of a series of 12Ce-TZP with different dopants. Selected micrographs are shown in Fig. 1 to demonstrate the different grain sizes. The grain size increases in the following order of solutes:

$$
\begin{aligned}
\mathrm{Ca}^{2+} & <\mathrm{Mg}^{2+}<\mathrm{Y}^{3+}<\mathrm{Yb}^{3+}<\mathrm{In}^{3+}<\mathrm{Sc}^{3+} \\
& <\mathrm{Ce}^{4+} \text { (base composition) } \leq \mathrm{Ti}^{4+}<\mathrm{Ta}^{5+} \leq \mathrm{Nb}^{5+}
\end{aligned}
$$

A comparison of the above ranking with the data of ionic radii and charges of the solutes leads to the following observations: (a) solutes of a lower valence are correlated with smaller grain sizes; (b) solutes of a larger radius are correlated with smaller grain sizes. Within the above series, there is no exception to the above correlations.

We have obtained data of grain growth kinetics over a range of temperatures for the 12Ce-TZP doped with $1 \mathrm{~mol} \%$ $\mathrm{Ca}^{2+}, \mathrm{Mg}^{2+}, \mathrm{Y}^{3+}, \mathrm{YB}^{3+}, \mathrm{In}^{3+}$, and $\mathrm{Sc}^{3+}$ in order to substantiate the above observations. In addition, undoped $12 \mathrm{Ce}-\mathrm{TZP}$ was also studied. We have plotted, in Fig. 2, the data of $1420^{\circ} \mathrm{C}$ assuming the following equation holds:

$$
d^{n}-d_{0}^{n}=K\left(t-t_{0}\right) \quad(n=2,3)
$$

In the above, $d$ is the grain size, at time $t, d_{0}$ is the reference grain size at time $t_{0}$, and $K$ is a temperature-dependent rate constant. When $n=2$, this is the so-called normal grain growth equation. In the above we have chosen, in most cases, the reference point as the 3 -h sintered one, provided the density at such time has already achieved $99 \%$. Otherwise, a longer $t_{0}$ is chosen to ensure the same high density. On a loglog plot, a good fit to Eq. (1) should have a slope of unity. Using this criterion, we find that the parabolic law gives a better representation of the data at $1420^{\circ}$ and $1500^{\circ} \mathrm{C}$, while the cubic law seems more satisfactory at $1300^{\circ} \mathrm{C}$. It is also noted that the relative order of the grain size among TZPs with different dopants remains the same throughout the temperature range studied. To make this clear, the temperature dependence of the rate constant in the parabolic law is plotted in Fig. 3, with the activation energy given next to the Arrhenius lines. A systematic decrease of the activation energy with increasing mobility is now apparent. Lastly, we note that the ranking of the solute in terms of its effect on grain size is the same as that found in Table II. For example, at $1420^{\circ} \mathrm{C}$, in Fig. 2, $\mathrm{Ca}^{2+}<\mathrm{Mg}^{2+}<\mathrm{Y}^{3+}<\mathrm{Yb}^{3+}<\mathrm{In}^{3+}<\mathrm{Sc}^{3+}<\mathrm{Ce}^{4+}$ (base composition).

In the theory of normal grain growth, the rate constant in Eq. (1) can be expressed as

$$
K=2 M \gamma
$$

In the above, $M$ is the mobility of the grain boundary and $\gamma$ is the grain-boundary energy. It is $M$, not $\gamma$, that can of ten be varied drastically by solute additions. Since the grain-boundary energies of these TZPs are not known, although they are not expected to vary by more than a factor of 2 to 3 , we shall let $\gamma=0.3 \mathrm{~J} / \mathrm{m}^{2}$ in order to compare the mobility in doped $12 \mathrm{Ce}-\mathrm{TZP}$ with data of other oxides compiled by Yan et al. ${ }^{22}$ Also available are the mobility data of 2 YTZP and $8 Y$ cubic zirconia published recently by our group. ${ }^{8}$ These data are shown in Fig. 4, in which $T_{m}$, the melting temperature, has been used for temperature normalization $\left(T_{m}=2700^{\circ} \mathrm{C}\right.$ for $\mathrm{ZrO}_{2}$ ). Clearly, the mobility of zirconia grain boundaries covers a fairly broad range at any given temperature. For example, a $12 \mathrm{Ce}-\mathrm{TZP}$ doped with 1 mol\% $\mathrm{CaO}$ has a mobility comparable to 2 Y-TZP, while the $8 Y$ cubic zirconia has a mo- 
Table II. Grain Sizes of 12Ce-TZP +1 mol\% MO

\begin{tabular}{|c|c|c|c|c|c|c|c|c|c|c|}
\hline \multirow[b]{2}{*}{ Solute } & \multicolumn{2}{|c|}{$2+$} & \multicolumn{4}{|c|}{$3+$} & \multicolumn{2}{|c|}{$4+$} & \multicolumn{2}{|c|}{$5+$} \\
\hline & $\mathrm{Ca}$ & $\mathrm{Mg}$ & $\mathrm{Y}$ & $\mathrm{Yb}$ & In & Sc & $\mathrm{Ce}$ & $\mathrm{Ti}$ & $\mathrm{Ta}$ & $\mathrm{Nb}$ \\
\hline Grain size $(\mu \mathrm{m})$ & 1.04 & 1.56 & 1.75 & 1.86 & 2.15 & 2.36 & 2.93 & 3.03 & 3.20 & 3.29 \\
\hline
\end{tabular}

bility at least an order of magnitude higher than $12 \mathrm{Ce}-\mathrm{TZP}$. It is also clear that the mobility of zirconia is not out of line with other ceramics when compared at the same homologous temperature. The activation energies and the prefactor of mobilities are listed in Table III.

\section{(3) Solute Segregation in Ce-TZP}

Direct evidence of solute segregation at the grain boundaries of $12 \mathrm{Ce}-\mathrm{TZP}$ was obtained by ESCA, AES, and STEM. Typical ESCA spectra demonstrating the above are shown in Fig. 5(A), in which both the spectrum taken from the as-fractured, intergranular surfaces and that after 3-min sputtering are compared. Using this technique, we have verified the segregation of $\mathrm{Mg}^{2+}, \mathrm{Sc}^{3+}, \mathrm{In}^{3+}$, and $\mathrm{Y}^{3+}$. The level of segregation for $\mathrm{In}^{3+}$ is somewhat higher than the rest of the trivalent group. This was presumably due to its volatility, which would drive $\mathrm{In}^{3+}$ toward grain boundaries to escape therefrom. The segregation of $\mathrm{Ta}^{5+}, \mathrm{Nb}^{5+}$ and $\mathrm{Ce}^{4+}$ was not detected. It should also be noted that Si peaks were searched for but not found in the above experiment. However, when $0.5 \mathrm{~mol} \%$ of $\mathrm{SiO}_{2}$ was intentionally added to $2 \mathrm{Y}-\mathrm{TZP}$, a $\mathrm{Si}^{4+}$ peak was detected on the grain boundary. Lastly $\mathrm{Ca}^{2+}, \mathrm{Yb}^{3+}$, and $\mathrm{Ti}^{4+}$ were not detected because of their low sensitivity factor or the overlapping peaks of $\mathrm{Zr}^{4+}$ and these elements.
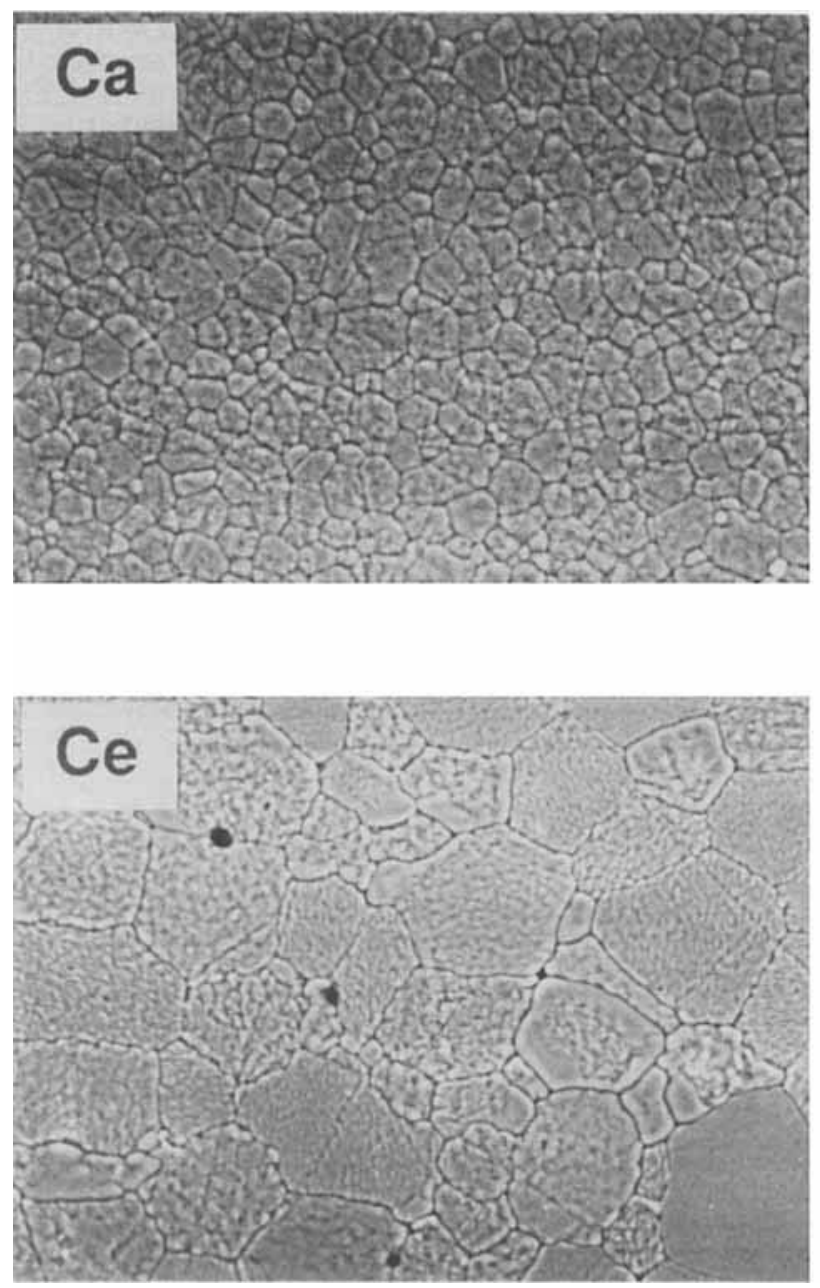

Because of the low bulk solute content, a direct determination of the enrichment factor was not possible. As an alternative, the following semiquantitative analysis was performed. We normalized the dopant peaks, $P_{\mathrm{D}}$, at the grain boundary by the host $\mathrm{Zr}$ peak, $P_{\mathrm{Zr}}$, with the relative elemental sensitivity factor $\zeta$ taken into account in the following way:

$$
S_{\mathrm{D}}=C_{0}\left(P_{\mathrm{D}} / \zeta_{\mathrm{D}}\right) /\left(P_{\mathrm{zr}} / \zeta_{\mathrm{zr}}\right)
$$

where $C_{0}$ is the bulk solute concentration (1\% in most cases). In the above, integrated peak intensity was used for $P_{\mathrm{D}}$ and $P_{\mathrm{Zr}}$, and the sensitivity factors were taken from Ref. 23. The enrichment factor $S_{\mathrm{D}}$ thus defined serves as an approximate index of the extent of grain-boundary segregation. The results are shown in Table IV.

We have performed a similar analysis using AES for the Ca-doped and Yb-doped 12Ce-TZP. The enrichment of $\mathrm{Ca}^{2+}$ can be seen in Fig. 5(B). Using the procedure above and Eq. (3), we obtained an enrichment factor equal to 5. The low-energy peak of $\mathrm{Yb}^{3+}$ cannot be differentiated from $\mathrm{Zr}^{4+}$ peaks, unfortunately, because of peak overlap. Higher-energy peaks were not possible because of surface charging problems. The AES results are also given in Table IV.

We have examined thin foil samples of Ca-doped $12 \mathrm{Ce}$ TZP using STEM. The signal of $\mathrm{Ca}^{2+}$ was detected readily at
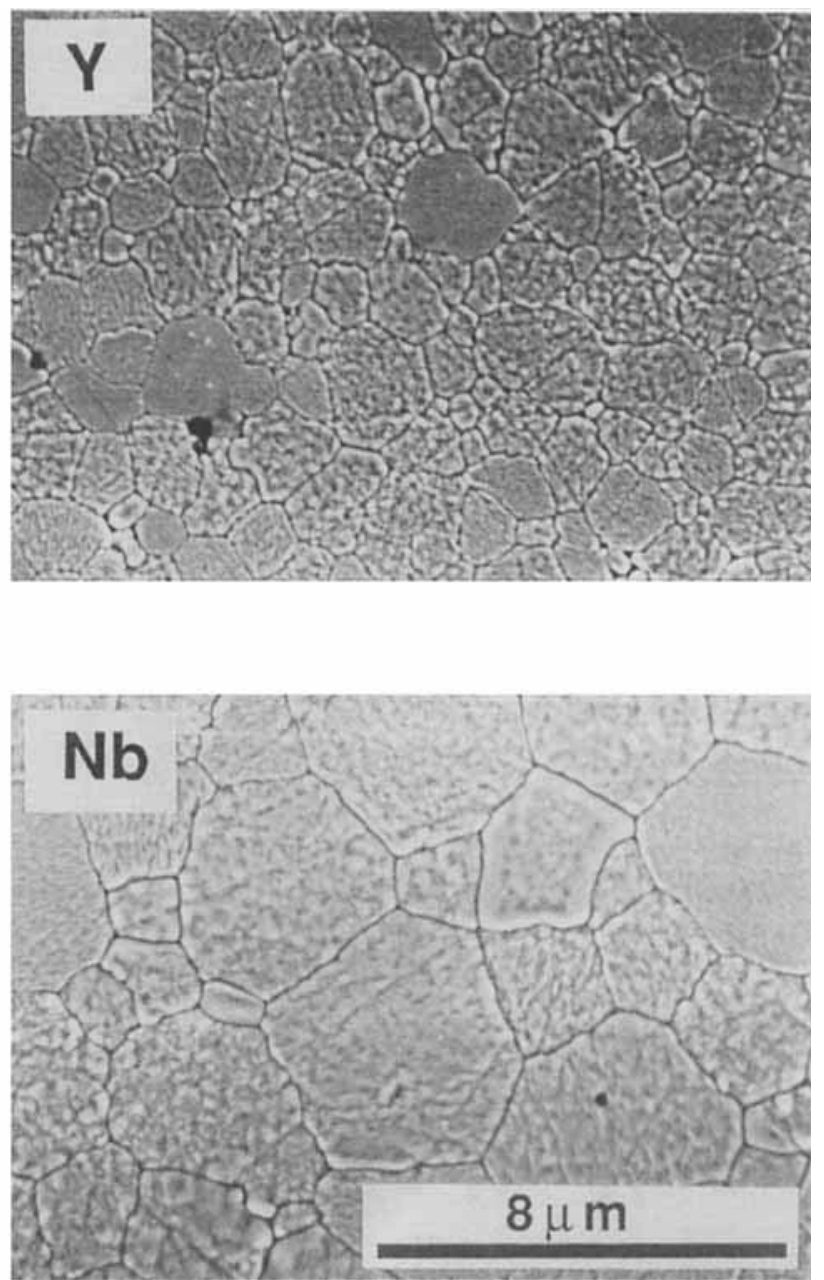

Fig. 1. Microstructure of $12 \mathrm{Ce}-\mathrm{TZP}$ sintered at $1400^{\circ} \mathrm{C}$ for $2 \mathrm{~h}$ and annealed at $1420^{\circ} \mathrm{C}$ for $12 \mathrm{~h}$; dopants indicated. 

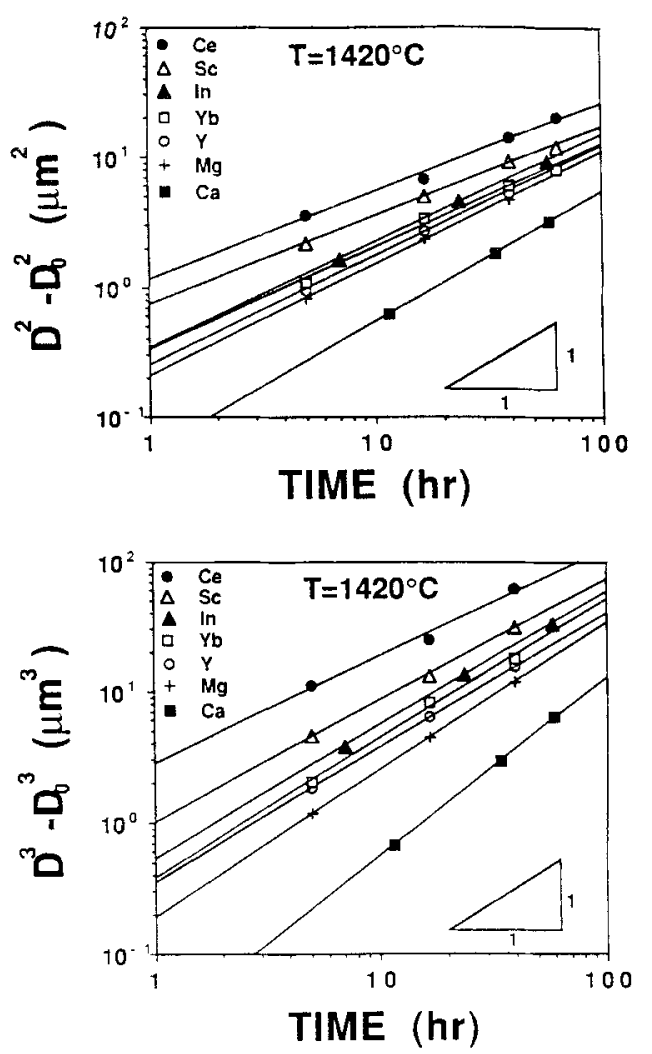

Fig. 2. Grain growth kinetics of $12 \mathrm{Ce}-\mathrm{TZP}$ at $1420^{\circ} \mathrm{C}$; dopants indicated.

the grain boundary, with a beam size of $5 \mathrm{~nm}$, but not within the grain. It should also be noted that Si-rich pockets could sometimes be detected at the triple junctions with a 1-nm glassy layer extended into all three grain boundaries. Si peaks could be seen from microanalysis of those regions. Similar observations were made on $\mathrm{Yb}^{3+}$-doped samples.

Summarizing the above data from ESCA, AES, and STEM, we find $\mathrm{Ca}^{2+}, \mathrm{Mg}^{2+}$, and $\mathrm{In}^{3+}$ segregate strongly, $\mathrm{Sc}^{3+}$ and $\mathrm{Y}^{3+}$ (and probably $\mathrm{Yb}^{3+}$ ) segregate moderately, and other dopants, including $\mathrm{Ce}^{4+}$, do not segregate or could not be studied. In addition, a Si-rich glassy layer exists at grain boundaries.

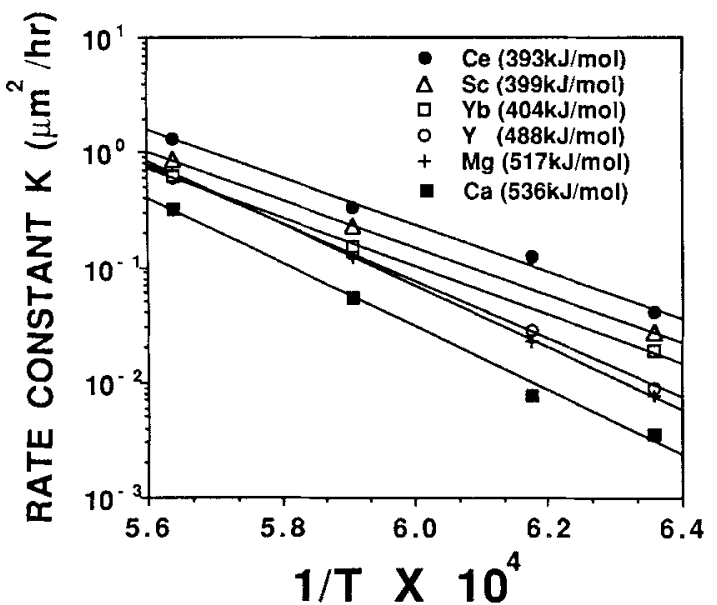

Fig. 3. Rate constant of the parabolic grain growth law against reciprocal temperature; dopants and activation energies indicated.

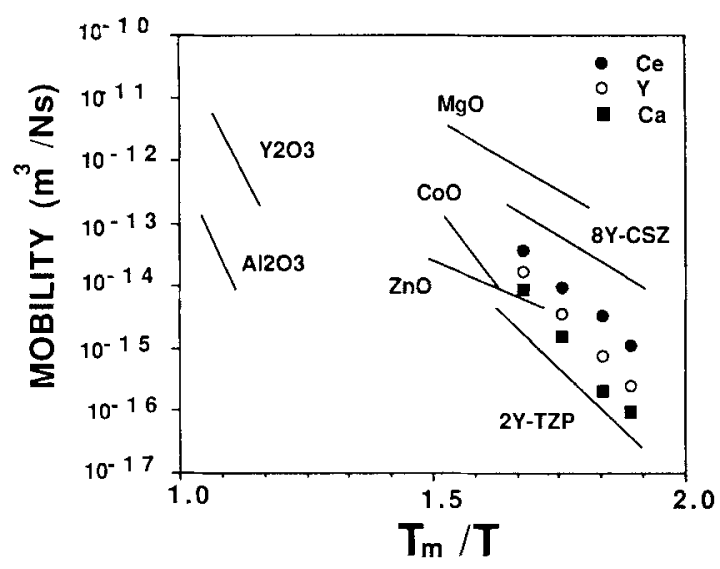

Fig. 4. Grain-boundary mobility of zirconia solid solutions and other oxides compared at the same homologous temperature. Data labeled as $\mathrm{Ce}$ are for $12 \mathrm{Ce}-\mathrm{TZP}$ and data labeled as $\mathrm{Y}$ and $\mathrm{Ca}$ are for $12 \mathrm{Ce}-\mathrm{TZP}$ with each dopant.

\section{(4) Segregation in Other TZPs}

In 2Y-TZP (containing $3.9 \mathrm{~mol} \% \mathrm{YO}_{1.5}$ ), $\mathrm{Y}^{3+}$ was found to segregate at the grain boundary, with an enrichment ratio of 1.9 according to ESCA results. Thus, cationic dopants from divalent to pentavalent ones were added to study cosegregation of $\mathrm{Y}^{3+}$ and the dopants. In addition, we have studied the effect of annealing atmosphere on segregation. These results are summarized in Table V. When dopants at a concentration of $0.6 \%$ substitution of cation sites were added, we found all except $\mathrm{Ce}^{4+}, \mathrm{Ti}^{4+}, \mathrm{Nb}^{5+}$, and $\mathrm{Ta}^{5+}$ segregated to the grain boundary. In the case of $\mathrm{Ce}^{4+} / \mathrm{Ce}^{3+}$, after annealing at $1300^{\circ}$ for $1 \mathrm{~h}$ in argon or hydrogen, $\mathrm{Ce}^{3+}$ was found to segregate strongly at the grain boundary. Overall, the segregation behavior of dopants in 2Y-TZP is exactly the same as that found in $12 \mathrm{Ce}-\mathrm{TZP}$, despite the different segregation tendencies of $\mathrm{Y}^{3+}$ and $\mathrm{Ce}^{4+}$ themselves.

We have also studied two other TZPs with trivalent stabilizers. These are a Sc-TZP with $6.2 \mathrm{~mol} \% \mathrm{ScO}_{1.5}$ and an InTZP with 8.6 mol\% $\mathrm{InO}_{1.5}$. In both cases, segregation of the trivalent stabilizers at grain boundaries was detected by ESCA. These results are also summarized in Table V.

\section{(5) Concentration of Dopant}

Since $\mathrm{Ca}^{2+}$ appears to be the most potent dopant for suppressing grain growth, it is of practical interest to examine the effect of $\mathrm{Ca}^{2+}$ concentration. We have measured the rate constant $K$ in Eq. (1), for $n=2$, at $1420^{\circ} \mathrm{C}$ for several $\mathrm{Ca}^{2+}$ concentrations. As shown in Fig. 6, the rate constant decreases monotonically with $\mathrm{Ca}^{2+}$ concentration between 0 and

Table III. Grain-Boundary Mobility $M$ of Zirconia Solid Solution*

\begin{tabular}{llc}
\hline $\begin{array}{c}\text { Composition } \\
\text { (solution in mol\%) }\end{array}$ & \multicolumn{1}{c}{$\begin{array}{c}M_{0} \\
\left.\left(\mathrm{~m}^{3} / \mathrm{N} \cdot \mathrm{s}\right)\right)\end{array}$} & $\begin{array}{c}Q \\
(\mathrm{~kJ} / \mathrm{mol})\end{array}$ \\
\hline $12 \mathrm{CeO}_{2}$ & $1.34 \times 10^{-2}$ & 393 \\
$12 \mathrm{CeO}_{2}, 1 \mathrm{ScO}_{1.5}$ & $1.29 \times 10^{-2}$ & 399 \\
$12 \mathrm{CeO}_{2}, 1 \mathrm{YbO}_{1.5}$ & $1.31 \times 10^{-2}$ & 404 \\
$12 \mathrm{CeO}_{2}, 1 \mathrm{YO}_{1.5}$ & 4.19 & 488 \\
$12 \mathrm{CeO}_{2}, 1 \mathrm{MgO}$ & 30.5 & 517 \\
$12 \mathrm{CeO}_{2}, 1 \mathrm{CaO}$ & 51.7 & 536 \\
$3_{1.9 \mathrm{YO}_{1.5}(2 \mathrm{YTZ}-\mathrm{TZ})}$ & $2.24 \times 10^{-2}$ & 445 \\
$14.8 \mathrm{YO}_{1.5}(8 \mathrm{Y}-\mathrm{CSZ})$ & $3.74 \times 10^{-5}$ & 284 \\
\hline${ }^{*} M=M_{0} \exp (-Q / R T)$. & &
\end{tabular}



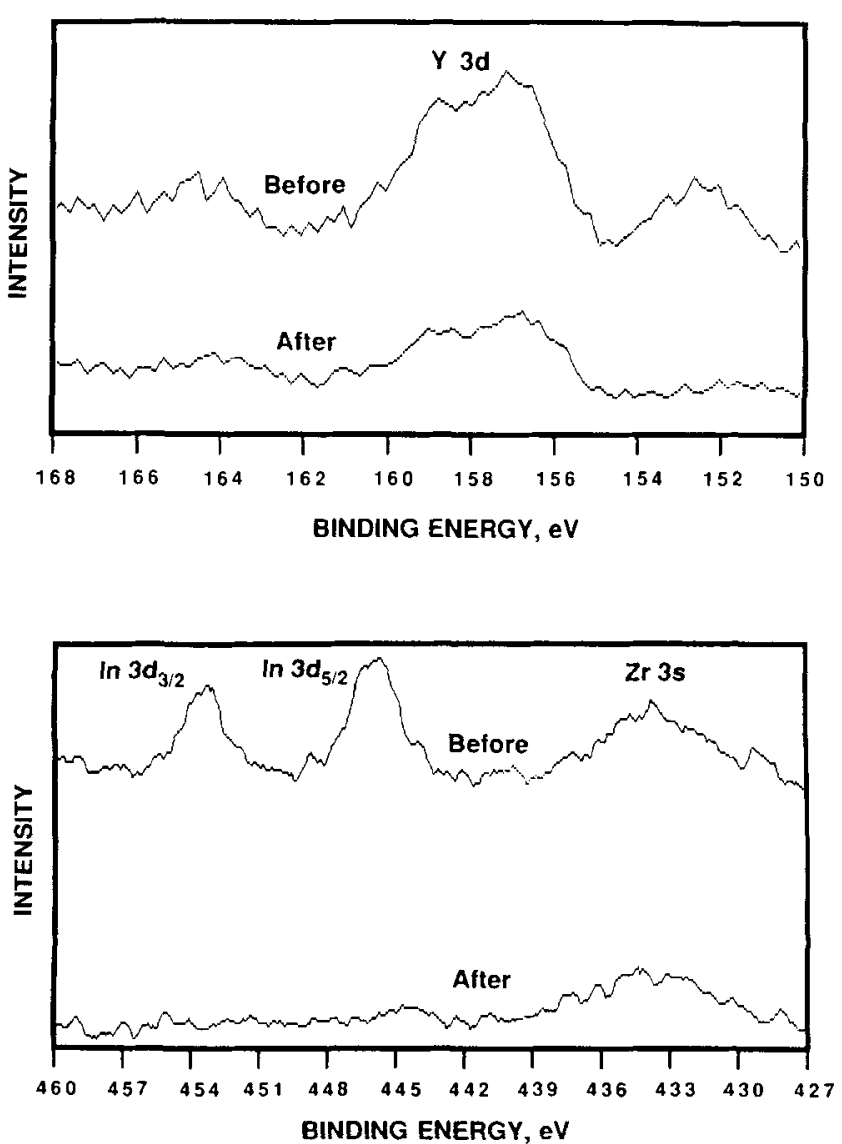

(A)

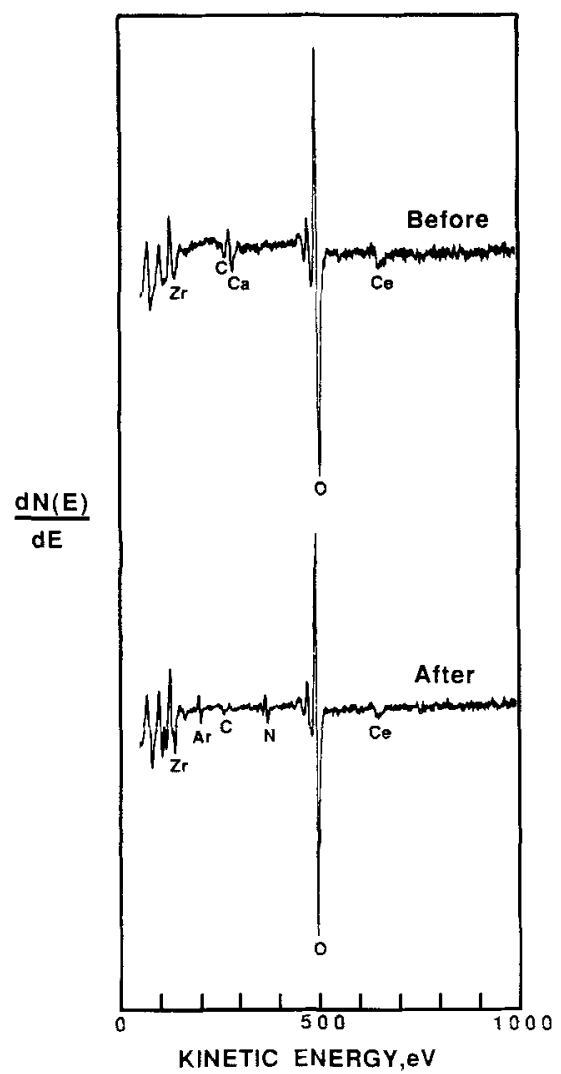

(B)

Fig. 5. (A) ESCA spectra of two intergranularly fractured $12 \mathrm{Ce}$ TZP doped separately with $Y$ and In. Spectra after argon ion sputtering also shown. (B) AES spectra of intergranularly fractured $12 \mathrm{Ce}-\mathrm{TZP}$ doped with $\mathrm{Ca}$. Spectrum after argon ion sputtering also shown.
Table IV. Solute Segregation at 12Ce-TZP Grain Boundaries

\begin{tabular}{ccc}
\hline Solute & $\begin{array}{c}\text { Enrichment factor } \\
C_{g_{b}} / C_{\text {buik }}\end{array}$ & Method \\
\hline $\mathrm{Ca}$ & 5 & Auger \\
$\mathrm{Mg}$ & 6.5 & ESCA \\
$\mathrm{Y}$ & 2 & ESCA \\
$\mathrm{Sc}$ & 2.3 & ESCA \\
$\mathrm{In}$ & 7.8 & ESCA \\
\hline
\end{tabular}

Table V. Solute Segregation at $t-\mathrm{ZrO}_{2}$ Grain Boundaries

\begin{tabular}{lc}
\hline $\begin{array}{c}\text { Solute } \\
(\text { mol\% })\end{array}$ & $\begin{array}{c}\text { Enrichment factor } \\
\mathrm{C}_{\text {gb }} / \mathrm{C}_{\text {bulk }}\end{array}$ \\
\hline $3.9 \mathrm{YO}_{1.5}$ & 1.9 \\
$3.9 \mathrm{YO}_{1.5}, 0.3 \mathrm{MgO}$ & $1.9(\mathrm{Y}), 6.0(\mathrm{Mg})$ \\
$3.9 \mathrm{YO}_{1.5}, 0.3 \mathrm{CeO}_{2}$ & $1(\mathrm{Ce})$ \\
$3.9 \mathrm{YO}_{1.5}, 0.3 \mathrm{CeO}_{1.5}$ & $>10(\mathrm{Ce})^{*}$ \\
$6.2 \mathrm{ScO}_{1.5}$ & 2.0 \\
$8.6 \mathrm{InO}_{1.5}$ & 4.5 \\
\hline *In hydrogen. &
\end{tabular}

1 mol\%. Thus, it is verified that the effect of $\mathrm{Ca}^{2+}$ increases with its concentration. At concentrations higher than $1 \mathrm{~mol} \%$, the two-phase field of tetragonal and cubic phases was entered. For example, cubic grains were observed at a volume fraction of $10 \%$ at $\mathrm{Ca}^{2+}$ concentration of $1.5 \mathrm{~mol} \%$. However, since cubic grains are relatively large and thus distant from each other, compared to tetragonal grains, they have little pinning effect on the growth of tetragonal grains, at least initially. A more detailed study of the kinetics of grain growth of the two-phase region is in progress.

\section{Theoretical Considerations}

\section{(1) Electrostatics}

To theoretically predict the electrostatic potential and the charge distribution in the double layer near lattice discontinuities, knowledge of the formation energies of cation vacancies and anion vacancies, as well as binding energies between dopant and point defects, is required. For tetragonal zirconia, no quantitative information on these properties is available, although it is known that anion vacancies are the predominant point defects. This information alone is sufficient for making the qualitative prediction that pure $\mathrm{ZrO}_{2}$ possesses a negatively charged grain boundary if we assume that the formation energy of an anion vacancy is smaller than that of a

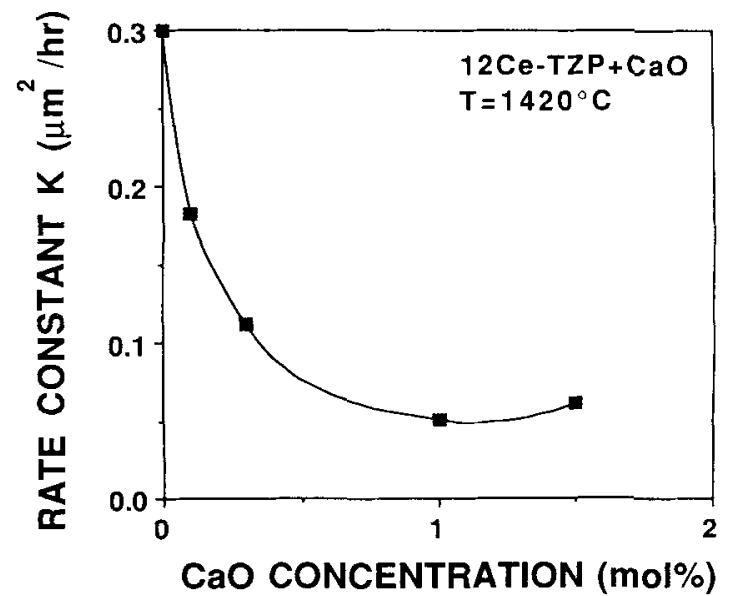

Fig. 6. Rate constant of the parabolic grain growth law of $12 \mathrm{Ce}$ $\mathrm{TZP}$ vs dopant $(\mathrm{CaO})$ concentration at $1420^{\circ} \mathrm{C}$. 
cation vacancy. For an illustration of the concept, we have sketched defect concentrations in Fig. 7. Note that charge balance is maintained in the bulk while thermal equilibrium is reached at the grain boundary. A negatively charged grain boundary with a negative electrostatic potential as sketched is thus necessary to fulfill the above two requirements. If divalent and trivalent cations substitute for $\mathrm{Zr}^{4+}$, at a concentration higher than that of the intrinsic point defects, then the grain boundary is reversed to possess a positive charge. This is also illustrated for the case of $\mathrm{Ca}$ doping in Fig. 7, where similar requirements of charge neutrality in the bulk and defect equilibrium at the boundary can be fulfilled by reversing the grain-boundary charge and electrostatic potential. In between, at a special temperature-dopant concentration condition, the grain boundary remains neutral. This condition is referred to as the isoelectric point. Theoretical predictions suggest that the isoelectric temperature increases with the dopant concentration. ${ }^{3}$

We have estimated in the Appendix the concentration of intrinsic anion vacancies in pure $\mathrm{ZrO}_{2}$. We find that, in order for intrinsic anion vacancies to dominate over $1 \%$ cation dopants, a temperature higher than $2400^{\circ} \mathrm{C}$ must be exceeded. Thus, over the temperature range studied here, the grainboundary charge is determined by the dopants.

Our data indicate that, generally, divalent and trivalent cations segregate to the grain boundary, but tetravalent and pentavalent cations do not. These observations strongly suggest that the grain boundaries are positively charged in $12 \mathrm{Ce}$ TZP, 2Y-TZP, and other TZPs stabilized by trivalent cations so that only cations with a negative effective charge are attracted to the lattice discontinuities as a space charge. These results can be understood in the following way:

(a) 2Y-TZP with a small amount of other dopants-The positive grain-boundary charge is induced by the majority aliovalent species, i.e., $\mathrm{Y}^{3+}$; similar cases are encountered in $\mathrm{Sc}-\mathrm{TZP}$ and $\mathrm{In}-\mathrm{TZP}$, i.e., $\mathrm{Sc}^{3+}$ and $\mathrm{In}^{3+}$.

(b) Ce-TZP with divalent and trivalent dopants-The positive grain-boundary charge is induced by the aliovalent dopants, i.e., $\mathrm{Mg}^{2+}, \mathrm{Ca}^{2+}, \mathrm{Sc}^{3+}, \mathrm{In}^{3+}, \mathrm{Yb}^{3+}$, and $\mathrm{Y}^{3+}$

(c) Ce-TZP with tetravalent dopants-It is known that some $\mathrm{Ce}^{3+}$ forms at high temperatures in air in $\mathrm{CeO}_{2}$. The

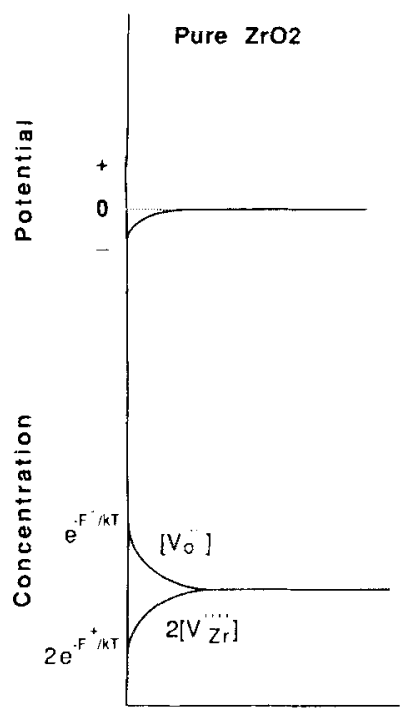

Distance from Boundary

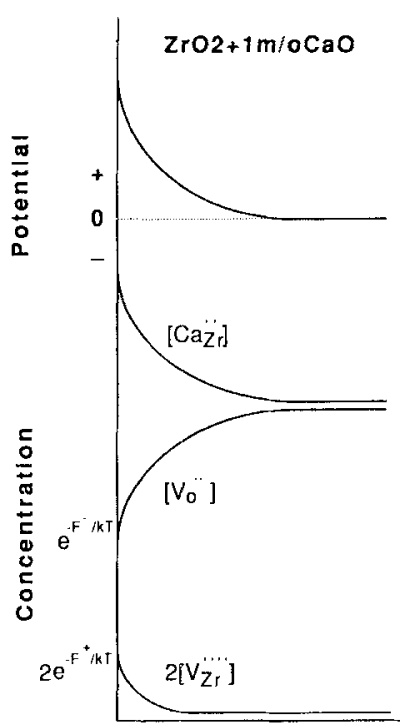

Distance from Boundary
Fig. 7. Schematic variations of electrostatic potential and defect concentrations with distance from grain boundary. Opposite grainboundary charges are developed in the intrinsic (pure $\mathrm{ZrO}_{2}$ ) and in the extrinsic $\left(\mathrm{ZrO}_{2}+1\right.$ mol\% $\left.\mathrm{CaO}\right)$ regimes. $(F=$ formation energy of $V_{\mathrm{Z}_{\mathrm{r}}}, F^{-}=$formation energy of $V_{\mathrm{O}}^{\prime \prime}$.) same undoubtedly also occurs in Ce-TZP. $\mathrm{Ce}^{3+}$ could thus serve as the requisite dopant that induces a positive charge on the grain boundary. By assuming that the $\mathrm{Ce}^{4+} / \mathrm{Ce}^{3+}$ ratio in Ce-TZP is the same as in $\mathrm{CeO}_{2}$, the concentration of $\mathrm{Ce}^{3+}$ is estimated in the Appendix and found sufficiently higher than those of intrinsic defects. Thus it should dominate the electrostatic behavior.

(d) Ce-TZP with pentavalent dopants $-\mathrm{Nb}^{5+}$ and $\mathrm{Ta}^{5+}$ are compensated by $\mathrm{Ce}^{3+}$ at high temperatures in $\mathrm{CeO}_{2}$, according to the study of Naik and Tien. ${ }^{24,25}$ The same presumably also occurs in Ce-TZP. The excess $\mathrm{Ce}^{3+}$ over and beyond that is then capable of inducing a positive charge on the grain boundary. To support this argument we have estimated the concentration of $\mathrm{Ce}^{3+}$, with $\mathrm{Nb}^{5+}$ or $\mathrm{Ta}^{5+}$ doping, in the Appendix and found $\mathrm{Ce}^{3+}$ always in excess.

(e) In principle, tetragonal $\mathrm{ZrO}_{2}$ with an appropriate amount of $\mathrm{Nb}^{5+}$ or $\mathrm{Ta}^{5+}$ dopants could possess a negatively charged grain boundary. This is not practical, however, for TZP of the composition $\mathrm{ZrO}_{2}-(\mathrm{Nb}, \mathrm{Ta})_{2} \mathrm{O}_{5}$ cannot be retained at room temperature. ${ }^{20}$ Thus, the most $\mathrm{Nb}^{5+}$ and $\mathrm{Ta}^{5+}$ can do in TZP is to shift the electrolytic condition slightly closer to the isoelectric point so that the grain boundary is less charged.

(f) Theoretically, $\mathrm{Zr}^{4+} / \mathrm{Zr}^{3+}$ reduction would also be the dominant mechanism responsible for the nonstoichiometry observed in pure $\mathrm{ZrO}_{2}$. If so, a positively charged grain boundary in pure $\mathrm{ZrO}_{2}$ should exist. All other arguments presented above still stand.

Based on the above argument, we believe that, in effect, all the TZPs currently known to us should have a positively charged grain boundary and a negative space charge made up of lower-valence cation segregants. In view of the above, we will limit our analysis below to divalent and trivalent dopants only.

\section{(2) Solute Drag}

Assuming the solute drag theory of $\mathrm{Cahn}^{26-28}$ is applicable in the present case, the grain-boundary mobility can be expressed as

$$
M=\frac{D}{\Delta C(k T)}
$$

In the above, $D$ is the diffusivity of the solute, $\Delta C$ is the excess concentration per unit grain-boundary area, and $k T$ has its usual meaning. In $\mathrm{ZrO}_{2}$ and its solid solutions, oxygen vacancy diffusion is much faster than cation diffusion. Thus, the main drag on the grain-boundary mobility comes from cation solutes. In the following, we will examine the dependence of $D$ and $\Delta C$ on the size and the charge of cation solutes in order to rationalize the grain size sequence reported in Table II.

In the case of attractive interactions, most of the excess solutes are localized near the grain boundary, and the drag force is due to short-range interactions between solutes and the grain boundary. ${ }^{26-28}$ Both elastic interactions and electrostatic interactions could be responsible for the attraction. Although its exact quantity is not known, the electrostatic potential in the double layer is probably of the order of 1 to $2 \mathrm{eV}$, in view of the calculated defect energies in fluorite structures recently reported. ${ }^{29,30}$ The elastic interaction can be estimated from the misfit energy. ${ }^{31}$

$$
U_{0}(\text { elastic })=\frac{2}{9} \mu \Omega\left(\frac{1+\nu}{1-\nu}\right) \alpha^{2}
$$

where $\mu$ is the shear modulus ( $80 \mathrm{GPa}$ ), $\Omega$ is the formula volume $\left(0.035 \mathrm{~nm}^{3}\right), \nu$ is Poisson's ratio $(0.3)$, and $\alpha$ is Vegard's slope for volume misfit given in Table I. The typical values of the elastic energy range from 0.02 to $0.29 \mathrm{eV}$ when $\alpha$ increases from 0.05 to 0.20 . Thus, the electrostatic interaction is much 
larger than elastic interactions likely to be present in the system. The contribution due to polarization is probably also small, judging from the numerical studies on the dipole contributions to space charge by Yan et al. ${ }^{32}$

In view of the above, we believe that in tetragonal zirconia, the attractive potential, electrostatic in origin, is primarily governed by the effective charge of the dopants and secondarily by the binding energy between these dopants and oxygen vacancies but is insensitive to ionic size, polarizability, and solubility. Dopants with a larger effective charge are expected to be more strongly attracted to the grain boundary as the dominant space charge. This is consistent with our data in Section III that divalent solutes (effective charge $=-2$ ) segregate stronger (and impede grain growth more) than trivalent solutes (effective charge $=-1$ ).

Our data also indicate that smaller dopants, such as $\mathbf{M g}^{2+}$ among divalent ones and $\mathrm{Sc}^{3+}$ among trivalent ones, result in a higher grain-boundary mobility. In the extreme case, the difference in mobilities can be an order of magnitude. Refering to Tables IV and V, we find that the variation in the enrichment factor among dopants of the same valence is not substantial. $\left(\mathrm{In}^{3+}\right.$ was excluded from this comparison because of its high vapor pressure.) Therefore, it seems more likely that the effect of ionic size is due to the faster diffusivity of smaller cations, i.e., $D$ rather than $\Delta C$ in Eq. (4). Although data for interdiffusion of solutes in TZP are not available, the above proposition is consistent with solute interdiffusivity in cubic zirconia ${ }^{33}$ and with several related observations in precipitate coarsening ${ }^{13}$ which implicates faster diffusivities of smaller ions relative to other trivalent and divalent cations.

\section{Discussion}

\section{(1) Grain Growth in TZP}

The solute drag mechanism was first proposed by Lee and Chen to be the cause of slower grain growth found in 2Y-TZP in comparison to that in $8 \mathrm{Y}$ cubic zirconia. ${ }^{8}$ In addition to a slower growth rate, they observed a much higher activation energy and a lower grain-boundary energy in 2Y-TZP. They argued that all such observations are consistent with grainboundary segregation and solute drag in 2Y-TZP and not in $8 Y$ cubic zirconia. Segregation of stabilizers in tetragonal zirconia to grain boundaries has not been reported before, although segregation of $\mathrm{Y}^{3+}$ to the free surfaces has been known for some time through the work of Auger electron spectroscopy. Based on the latter observation, Burggraaf and co-workers had speculated that a similar trend occurred at tetragonal grain boundaries and could cause a grain growth suppression. ${ }^{34}$ The present study, by providing direct observations of segregation and a systematic comparison of different dopants, supports and extends Lee and Chen's conclusion to other TZP systems.

Concerning activation energies of mobility shown in Fig. 3 and Table III, a correlation between a higher activation energy and a lower mobility seems to hold. The temperature dependence of the mobility arises from two sources, the excess solute $\Delta C$ and the (lattice) interdiffusion of solute $D$, according to Eq. (4). If we further assume that isoelectric solutes segregate similarly, as suggested by their similar enrichment ratios, then the difference in activation energies among them is due to the diffusivity. Since larger solutes are expected to have a higher activation energy for lattice diffusion (also supported by diffusivity experiments ${ }^{33}$ ), the observed trend in activation energy is consistent with the overall picture thus far provided.

To appreciate the implication of the temperature dependence of $\Delta C$, the following preliminary estimation of segregation energy is helpful. We note the activation energies for lattice interdiffusion and self-diffusion in cubic zirconia are $423(\mathrm{Ca})$, $293(\mathrm{Mg}), 423(\mathrm{Y})$, and $391(\mathrm{Zr})$, all in units of $\mathrm{kJ} / \mathrm{mol} .{ }^{33}$ If we assume that these values are unchanged for $T Z P$, we can then compare them with $Q$ in Table III and attribute the difference to segregation energy. In this way, we find that the segregation energy of divalent cations $\left(\mathrm{Ca}^{2+}, \mathrm{Mg}^{2+}\right)$ is consistently higher than that of the trivalent cation $\left(\mathrm{Y}^{3+}\right)$. Taking $\mathrm{Ca}^{2+}$ as an example, the segregation energy is estimated to be $113 \mathrm{~kJ} / \mathrm{mol}$ or $1.22 \mathrm{eV}$. This value, though crude, seems reasonable. Presumably, it is this segregation energy which gives rise to the temperature dependence of $\Delta C$.

\section{(2) Strain Energy Argument}

Lange ${ }^{35-36}$ and co-workers have offered an entirely different proposition to explain the slow grain growth in stabilized TZP. ${ }^{35,36}$ They suggest that the tetragonal phase field is much narrower at $1300^{\circ}$ to $1500^{\circ} \mathrm{C}$, at equilibrium, than generally assumed, and that a suppression of grain growth is observed only in the "two-phase" field, which approaches equilibrium by solute partitioning over a very long time. Such a picture, however, does not provide a mechanism for the slow grain growth by itself unless the cubic phase is already present and serves as the pinning phase. The latter is unlikely since the cubic grains are typically much larger than tetragonal grains and are thus relatively few in number. To provide a mechanism for suppressing grain growth, they further propose that during grain growth, solute partitioning also proceeds to give rise to a strain energy as a result of the compositional dependence of lattice parameters. ${ }^{36}$ This rise in strain energy, according to this argument, suppresses grain growth. This latter proposal can be tested against the grain growth data reported here directly. Since In $^{3+}$ doping causes the least misfit, according to Table I, we should observe the fastest grain growth in this material. This is not the case in Figs. 2 and 4. Likewise, since $\mathrm{Ca}^{2+}$ doping causes less misfit than $\mathrm{Mg}^{2+}$ doping, the grain growth in $\mathrm{Mg}^{2+}$-doped Ce-TZP should be faster - again in contradiction to our results. Indeed, we must conclude that Lange's strain-energy argument is not borne out by the data of grain growth kinetics.

Data in Fig. 6 are similar to the observation made by Lange on the $\mathrm{Y}^{3+}$ concentration dependence of grain size in the $\mathrm{ZrO}_{2}-\mathrm{Y}_{2} \mathrm{O}_{3}$ system, yet we believe that the data can be easily rationalized by the proportionality between $\Delta C$ and $C_{0}$, which results in an inverse dependence of $M$ and $C_{0}$, according to Eq. (4). When a two-phase field is finally entered at higher concentrations, the mobility of tetragonal grain boundary will probably remain constant (being set by the solubility limit of the tetragonal phase) until the cubic phase fraction becomes high. This explains the shape of the curve in Fig. 6.

\section{(3) Role of a Glassy Phase}

We finally address the issue of the glassy grain-boundary phase which seems to exist ubiquitously in a zirconia system. First, we must state that the space charge should arise near any geometric discontinuity, including a phase boundary, which is a source and sink of point defects. ${ }^{3}$ Thus, even in the presence of a glassy layer between grains, the grain-boundary movement will experience a solute drag. Second, in the very fine grain ceramics that we have studied, the thickness of the glassy layer is about $1 \mathrm{~nm}$, which would be within the coherent length calculated by Clarke using a structural force model ${ }^{37}$ Thus, it is not surprising that adjacent grains interact in a way similar to grains across a "clean" boundary. This argument is further supported by the existence of the characteristic dihedral angle between tetragonal and cubic grains in the two-phase field. ${ }^{8}$ Third, for such thin grain boundaries, it is probable that diffusion across the glassy layer is fast compared to solute drag which is controlled by lattice diffusion. Thus, the mobility of a grain boundary, wetted by a small amount of glass, can still be rate-limited by solute drag via the space charge mechanism. In this regard, the overall grain growth kinetics of a slightly glass-containing ceramic is not mechanistically different from that of a glass-free ceramic. 


\section{Conclusions}

(a) In all the cases of practical interest, tetragonal zirconia possesses a positively charged grain boundary causing segregation of divalent and trivalent stabilizers to the grain boundaries, independent of ionic size and solubility.

(b) Grain-boundary mobility in TZP is primarily controlled by the space charge segregation of divalent and trivalent solutes, and secondly by the lattice diffusivities of these solutes: the largest divalent solute provides the strongest grain-boundary drag.

(c) The activation energy of grain-boundary mobility in TZP is higher than that of lattice interdiffusivity of dopants. The difference may be attributed to a segregation energy; the divalent solutes have a higher segregation energy than trivalent solutes.

(d) A sufficiently thin glassy layer has no effect on the applicability of the space charge concept. Thus, solute drag can still operate in slightly glass-containing ceramics of very fine grains.

\section{APPENDIX}

\section{Nonstoichiometry in $\mathrm{ZrO}_{2}$, Ce-TZP, and Nb-Doped Ce-TZP}

\section{(1) $\mathrm{ZrO}_{2}$}

Pure $\mathrm{ZrO}_{2}$ contains anion vacancies and may be written as $\mathrm{ZrO}_{2-x}$. According to the recent data of Aldebert et al., ${ }^{38} x$ varies from 0.001 at $1925^{\circ} \mathrm{C}$ to 0.052 at $2410^{\circ} \mathrm{C}$ in a helium atmosphere. Extrapolating these data to lower temperatures, the values of $x$ are given in Fig. A1. These values are representative of the concentration of the intrinsic vacancies. Clearly, they are much smaller than the typical dopant concentrations used in this study.

\section{(2) $\mathrm{CeO}_{2}$ and $\mathrm{Ce}-\mathrm{TZP}$}

Pure $\mathrm{CeO}_{2}$ contains anion vacancies, compensated by concurrent reduction of $\mathrm{Ce}^{4+}$ to $\mathrm{Ce}^{3+}$. Thus, it may be written as $\mathrm{Ce}_{1-2 x}^{4+} \mathrm{Ce}_{2 x}^{3+} \mathrm{O}_{2-x} . \mathrm{Ce}^{3+}$ is responsible for a type of electronic conductivity, via the so-called small polaron mechanism. ${ }^{22}$ The latter has a very small activation energy, ca. $0.15 \mathrm{eV}$, compared to that of the $\left[\mathrm{Ce}^{3+}\right]$, ca. $2.1 \mathrm{eV}$. Thus, the nonstoichiometry and $\left[\mathrm{Ce}^{3+}\right]$ can be determined by conductivity indirectly. ${ }^{24}$

Naik and Tien found a correlation between electrical conductivity $\sigma$ and $x$ of the following form: ${ }^{24.25}$

$$
\left[\mathrm{Ce}^{3+}\right]_{\text {intrinsic }}=2 x=2.3 \times 10^{-2} \sigma\left(\Omega^{-1} \cdot \mathrm{cm}^{-1}\right)
$$

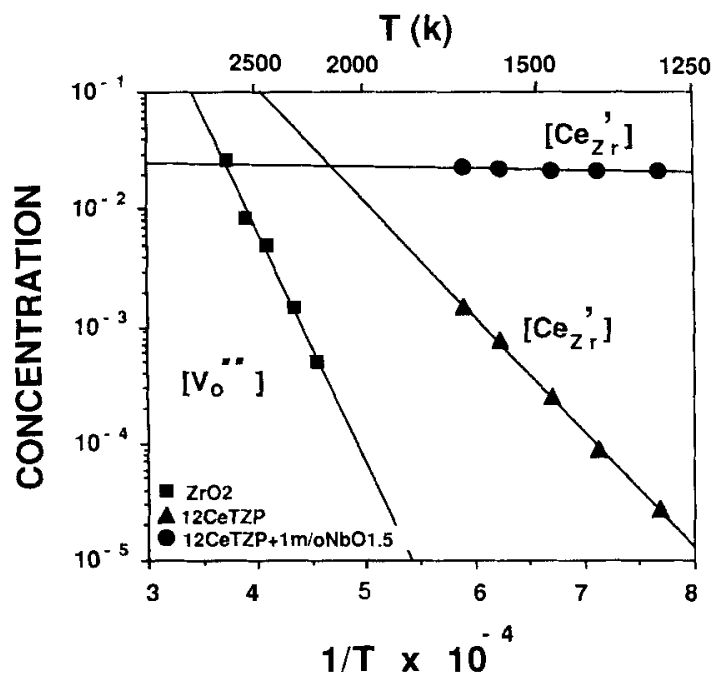

Fig. A1. Defect concentrations vs reciprocal temperature for pure $\mathrm{ZrO}_{2}$ and its solid solutions (see text). between $900^{\circ}$ and $1329^{\circ} \mathrm{C}$, through conductivity and thermogravimetric experiments in $\mathrm{CeO}_{2}$. From their conductivity data at $1420^{\circ}, 1329^{\circ} \mathrm{C}$, and below, we can estimate $\left[\mathrm{Ce}^{3+}\right]$ in pure $\mathrm{CeO}_{2}$. Assuming $\left[\mathrm{Ce}^{3+}\right]$ in $12 \mathrm{Ce}-\mathrm{TZP}$ is $12 \%$ of the above, we plot the estimated $\left[\mathrm{Ce}^{3+}\right]$ in $12 \mathrm{Ce}-\mathrm{TZP}$ in Fig. A1. Clearly, in the absence of aliovalent dopants, $\left[\mathrm{Ce}^{3+}\right]$ is sufficiently abundant between $1000^{\circ}$ and $2000^{\circ} \mathrm{C}$ to be the predominant charged species.

\section{(3) 12Ce-TZP Doped with $\mathrm{Nb}^{5+}$ and $\mathrm{Ta}^{5+}$}

Naik and Tien reported that $\mathrm{Nb}^{5+}$ dopants in $\mathrm{CeO}_{2}$ at high temperatures were accommodated by replacing equal numbers of $\mathrm{Ce}^{4+}$ and formation of $\mathrm{Ce}^{3+} \cdot{ }^{24,25}$ Thus, the $\mathrm{Nb}$-doped $\mathrm{CeO}_{2}$ may be written as $\mathrm{Ce}_{1-2 x-y}^{4+} \mathrm{Ce}_{2 x+y}^{3+} \mathrm{Nb}_{y}{ }^{5+} \mathrm{O}_{2-x}$ to account for both the intrinsic and the extrinsic defects. Assuming the same mobility of electrons by the small polaron mechanism we have calculated $\left[\mathrm{Ce}^{3+}\right]$ in a $\mathrm{CeO}_{2}-0.40 \mathrm{~mol} \% \mathrm{Nb}_{2} \mathrm{O}_{5}$ at $1029^{\circ}$ and $1420^{\circ} \mathrm{C}$, from the conductivity data of Naik and Tien. ${ }^{24,25}$ Comparing $\left[\mathrm{Ce}^{3+}\right]$ in the $\mathrm{Nb}^{5+}$-doped (extrinsic) case and the undoped (intrinsic) case estimated in Section (2), we find the following relation being observed closely:

$$
\left[\mathrm{Ce}^{3+}\right]_{\text {extrinsic }}=\left[\mathrm{Ce}^{3+}\right]_{\text {intrinsic }}+\left[\mathrm{Nb}^{5+}\right]
$$

at these temperatures. This conclusion is also supported by the closeness of the thermogravimetric data of the doped and undoped $\mathrm{CeO}_{2}$ at high temperatures. ${ }^{24,25}$ Assuming the same mechanism of $\mathrm{Nb}^{5+} / \mathrm{Ce}^{3+}$ compensation operates in $12 \mathrm{Ce}$ TZP, we have calculated the total concentration of $\mathrm{Ce}^{3+}$ with $1 \% \mathrm{Nb}^{5+}$ dopants and plotted it in Fig. A1.

Acknowledgments: We are grateful to Dr. T.S. Sheu for providing Sc- and In-stabilized zirconia and to Mr. T.Y. Syau for performing Auger microanalysis.

\section{References}

1J. Frenkel, Kinetic Theory of Liquids; p. 36. Oxford University Press, New York, 1946.

${ }^{2}$ J. D. Eshelby, E. Newey, P. Pyatt, and A. Lidiard, "Changed Dislocations and the Strength of Ionic Crystals," Philos. Mag., 3, 75-89 (1958).

${ }^{3}$ K. L. Kliewer and J. S. Koehler, "Space Charge in Ionic Crystals, I. General Approach with Application to NaCl," Phys. Rev, 140 [4A] A1226-40 (1965).

${ }^{4}$ W. D. Kingery, "Possible Concepts Necessary and Sufficient for Interpenetration of Ceramic Grain-Boundary Phenomena: I, Grain-Boundary Characteristics, Structure, and Electrostatic Potential," J. Am. Ceram. Soc., 57 [1] 1-12 (1974); "II, Solute Segregation, Grain-Boundary Diffusion, and General Discussions," ibid., 57 [2] 74-83 (1974).

${ }^{5}$ W. D. Kingery, T. Mitamura, J. B. Vander Sande, and E. L. Hall, "Boundary Segregation of $\mathrm{Ca}, \mathrm{Fe}, \mathrm{Ca}$, and $\mathrm{Si}$ in $\mathrm{MgO}$," J. Mater. Sci., 14, 1766-67 (1979).

${ }^{6}$ Y. M. Chiang, A. F. Henriksen, W. D. Kingery, and D. Finello, "Characterization of Grain-Boundary Segregation in MgO,"J. Am. Ceram. Soc., 64 [7] 385-89 (1981).

${ }^{7}$ C.-W. Li and W. D. Kingery, "Solute Segregation at Grain Boundaries in Polycrystalline $\mathrm{Al}_{2} \mathrm{O}_{3}$ "; pp. 368-78 in Advances in Ceramics, Vol. 10, Structure and Properties of $\mathrm{MgO}$ and $\mathrm{Al}_{2} \mathrm{O}_{3}$ Ceramics. Edited by W. D. Kingery. American Ceramic Society, Columbus, OH, 1984.

${ }^{8}$ I. G. Lee and I-W. Chen, "Sintering and Grain Growth in Tetragonal and Cubic Zirconia"; pp. 340-45 in Sintering '87. Edited by S. Somiya, M. Shimada, M. Yoshimura, and R. Watanabe. Elsevier Applied Science, London, U.K., 1988.

"M. Rühle, N. Claussen, and A.H. Heuer, "Microstructural Studies of $\mathrm{Y}_{2} \mathrm{O}_{3}$-Containing Tetragonal $\mathrm{ZrO}_{2}$ Polycrystals (Y-TZP)"; pp. 352-70 in Advances in Ceramics, Vol. 12, Science and Technology of Zirconia II. Edited by N. Claussen M. Rühle, and A. H. Heuer, American Ceramic Society, Columbus, $\mathrm{OH}, 1984$.

${ }^{10}$ R. D. Shannon, "Revised Effective Ionic Radii and Systematic Studies of Interatomic Distances, Halides and Chalcogenides," Acta Crystallogr., A32, 756 (1976).

${ }^{11}$ S. M. Sim and V. S. Stubican, "Phase Relations and Ordering in the System $\mathrm{ZrO}_{2}-\mathrm{MgO}$," J. Am. Ceram. Soc., 70 [7] 521-26 (1987).

${ }^{12}$ T.Y. Tien and E. C. Subbarao, "X-ray and Electrical Conductivity Study of Fluorite Phase in the System $\mathrm{ZrO}_{2}-\mathrm{CaO}$," J. Chem. Phys., 39 [4] 1041-47 (1963).

${ }^{13}$ T.-S. Sheu, "Phase Stability of Zirconia Solid Solutions"; Ph.D. Thesis. University of Michigan, Ann Arbor, MI, (1989).

${ }^{14} \mathrm{H}$. Toraya, "Effect of $\mathrm{YO}_{15}$ Dopant on Unit-Cell Parameters of $\mathrm{ZrO}_{2}$ at Low Contents of YO 1.5 ," J. Am. Ceram. Soc., 72 [4] 662-64 (1989).

${ }^{15}$ H. G. Scott, "Phase Relationships in the Zirconia-Yttria System," 
J. Mater. Sci., 10 1527-35 (1975).

${ }^{16}$ D. C. Agrawal, R. Gopalakrishnon, and D. Chakravorty, "Phase and Microstructures in Zirconia-Calcia-Titania Multiphase Ceramics," $J$. $\boldsymbol{A m}$. Ceram. Soc., 72 [6] 912-15 (1989).

${ }^{17}$ M. J. Bannister and J. M. Barnes, "Solubility of $\mathrm{TiO}_{2}$ in $\mathrm{ZrO}_{2}$," J. Am. Ceram. Soc., 69 [11] C-269-C-271 (1986).

${ }^{18} \mathrm{E}$. Tani, M. Yoshimura, and S. Somiya, "Revised Phase Diagram of the System $\mathrm{ZrO}_{2}-\mathrm{CeO}_{2}$ below $1400^{\circ} \mathrm{C}$," J. Am. Ceram. Soc., 66 [7] 506-10 (1983).

${ }^{19} \mathrm{~K}$. Urabe, K. Ogata, H. Ikawa, and S. Udagawa, "Phase Transformation and Lattice Constants of Zirconia Solid Solutions in the System $\mathrm{Y}_{2} \mathrm{O}_{3}$ $\mathrm{CeO}_{2}-\mathrm{ZrO}_{2}$ "; pp. 147-52 in Materials Science Forum, Vol. 34-36, Ceramic Developments. Edited by C.C. Sorrell and B. Ben-Nissan. Trans Tech Publications, Aedermannsdorf, Switzerland, 1988.

${ }^{20}$ D. J, Kim, "The Effect of Alloying on the Transformability of $\mathrm{Y}_{2} \mathrm{O}_{3}$ Stabilized Tetragonal $\mathrm{ZrO}_{2}$ "; Ph.D. Thesis. University of Michigan, Ann Arbor, MI, 1988

${ }^{21}$ M. Yoshimura, "Phase Stability of Zirconia," Am. Ceram. Soc. Bull., 67 [12] 1950-55 (1988)

${ }^{22}$ M. F. Yan, R. M. Cannon, and H. K. Bowen. "Grain Boundary Migration in Ceramics"; pp. 276-307 in Ceramic Microstructure '76. Edited by R. M. Fulrath and J. A. Pask. Westview Press, Boulder, CO, 1977.

${ }^{23}$ C. P. Wagner, W. R. Riggs, L. E. Davis, J. F. Moulder, and G. E. Muilenberg, Handbook of X-ray Photoelectron Spectroscopy. Perkin-Elmer Corp., Eden Prairie, MN, 1979.

${ }^{24}$ I. K. Naik and T.Y. Tien, "Small Polaron Mobility in Non-Stoichiometric Cerium Dioxide," J. Phys. Chem. Solids, 38 [3] 311-15 (1978).

${ }^{25}$ I. K. Naik and T.Y. Tien, "Electrical Conduction in $\mathrm{Nb}_{2} \mathrm{O}_{5}$-Doped Cerium Oxides," I. Electrochem. Soc., 126 [4] 562-66 (1979).

${ }^{26} \mathrm{~J} . W$. Cahn, "The Impurity Drag Effect in Grain Boundary Motion," Acta Metall., 10 [9] 789-98 (1962).

${ }^{27}$ K. Lücke and H. P. Stüwe, "On the Theory of Impurity Controlled Grain Boundary Motion," Acta Metall., 19 [10] 1087-99 (1971).

${ }^{28}$ D. J. Srolovitz, R. Eykholt, D. M. Barnett, and J. P. Hirth, "Moving Discommensurations Interacting with Diffusing Impurities," Phys. Rev B, 35
[12] 6107-21 (1987).

${ }^{29}$ W. C. Mackrodt and P. M. Woodrow, "Theoretical Estimates of Point Defect Energies in Cubic Zirconia,"J. Am. Ceram. Soc., 69 [3] 277-80 (1986).

${ }^{30}$ A. Dwivedi and A. N. Cormack, "A Computer Simulation Study of the Defect Structure of Calcia-Stabilized Zirconia," Philos. Mag. A, 61 [1] 1-22 (1990).

31 J. D. Eshelby, "Determination of the Elastic Field of an Ellipsoidal Inclusion and the Related Problems," Proc. R. Soc. London, A, 241, 376-96 (1957).

${ }^{32}$ M. F. Yan, R. M. Cannon, and H. K. Bowen, "Space Charges, Elastic Field and Dipole Contributions to Equilibrium Solute Segregation at Interfaces," J. Appl. Phys., 54 [2] 764-78 (1983).

${ }^{33}$ Y. Oishi, K. Ando, and Y. Sakka, "Lattice and Grain-Boundary Diffusion Coefficients of Cations in Stabilized Zirconias"; pp. 208-19 in Advances in Ceramics, Vol. 7, Characterization of Grain Boundaries. Edited by M.F. Yan and A. H. Heuer. American Ceramic Society, Columbus, OH 1983

${ }^{34}$ A. J. A. Winnubst and A. J. Burggraaf, "The Aging Behavior of UltrafineGrained Y-TZP in Hot Water"; pp. 39-47 in Advances in Ceramics, Vol. 24A, Science and Technology of Zirconia III. Edited by S. Somiya, N. Yamamoto, and H. Hanagida. American Ceramic Society, Westerville, $\mathrm{OH}$, 1988.

${ }^{35} \mathrm{~F} . \mathrm{F}$. Lange, "Transformation Toughened $\mathrm{ZrO}_{2}$ : Correlations Between Grain Size Control and Composition in the $\mathrm{ZrO}_{2}-\mathrm{Y}_{2} \mathrm{O}_{3}$ System," J. Am. Ceram. Soc., 69 [3] 240-42 (1986).

${ }^{36}$ F. F. Lange, D. B. Marshall, and J. B. Porter, "Controlling Microstructures Through Phase Partitioning from Metastable Precursors: The $\mathrm{ZrO}_{2}$ $\mathrm{Y}_{2} \mathrm{O}_{3}$ System"; pp. 519-32 in Ultrastructure Processing of Advanced Ceramics. Edited by J. K. Mackenzie and D. R. Ulrich. Wiley, New York 1988.

${ }^{37}$ D. R. Clarke, "On the Equilibrium Thickness of Intergranular Glassy Phases in Ceramic Materials," J. Am. Ceram. Soc., 70 [1] 15-22 (1987).

${ }^{38} \mathrm{P}$. Aldebert and J.-P. Travers, "Structure and Ionic Mobility of Zirconia at High Temperature," J. Am. Ceram. Soc., 68 [1] 34-40 (1985). 